\title{
Stria terminalis lesions attenuate the effects of posttraining oxotremorine and atropine on retention
}

\author{
INES B. INTROINI-COLLISON, YUTAKA ARAI, and JAMES L. MCGAUGH \\ University of California, Irvine, California
}

\begin{abstract}
In these experiments, we examined the effects of posttraining administration of the cholinergic agonist oxotremorine and the cholinergic antagonist atropine on retention in rats with lesions of the stria terminalis (ST). Male Sprague-Dawley rats, with either sham or bilateral ST lesions, were trained in a one-trial step-through inhibitory-avoidance task and a Y-maze discrimination task. Immediately after training on each task, they received i.p. injections of saline, oxotremorine $(50.0 \mu \mathrm{g} / \mathrm{kg})$, or atropine $(3.0 \mathrm{mg} / \mathrm{kg}$ ). Retention of each task was tested 1 week following training. Lesions of the ST did not affect retention of either task in otherwise untreated animals, but blocked both the memory-enhancing effect of oxotremorine and the memory-impairing effect of atropine. These findings suggest that activation of pathways within the ST is involved in cholinergic influences on memory, and are consistent with the view that the amygdaloid complex is involved in integrating neuromodulatory influences on memory storage.
\end{abstract}

The findings of numerous studies have implicated central muscarinic-cholinergic mechanisms in memory storage (Bartus, Dean, Goss, \& Lippa, 1980; Bartus, Dean, Pontecorvo, \& Flicker, 1985; Davies, 1985; Karczmar \& Dun, 1978; Russell, 1982; Stratton \& Petrinovich, 1963). In general, cholinomimetic agents facilitate memory (Dunnett, 1985; Flood, Smith, \& Cherkin, 1983, 1984, 1985; Haroutunian, Kanof, \& Davis, 1985; Introini \& Baratti, 1984; Introini-Collison \& McGaugh, 1988; Murray \& Fibiger, 1985), whereas muscarinic receptor antagonists induce amnesia (Drachman, 1977; Drachman \& Leavitt, 1974; Flood, Landry, \& Jarvik, 1981; Introini \& Baratti, 1984; Introini-Collison \& McGaugh, 1988). These effects have been observed in a wide variety of tasks, including an appetitively motivated task (Stratton $\&$ Petrinovich, 1963), active avoidance (Flood et al., 1981), inhibitory avoidance (Gower, 1987; IntroiniCollison \& McGaugh, 1988), and aversively motivated discrimination learning (Introini-Collison \& McGaugh, 1988). These findings suggest that acetylcholine released during or immediately after training is involved in the modulation of memory storage (McGaugh, 1989).

Recent evidence suggests that opioid peptidergic systems interact with the cholinergic system during memory storage. Posttraining administration of oxotremorine and naloxone, in doses that are subeffective by themselves, significantly facilitate retention when given together immediately posttraining (Baratti, Introini, \& Huygens, 1984). Furthermore, atropine blocks the memoryfacilitating effects of naloxone, whereas oxotremorine an-

This research was supported by Research Grants MH12526 and NIDA from NIMH and by Contract N00014-87-K-0518 from the Office of Naval Research. Address correspondence to Ines B. Introini-Collison, Center for the Neurobiology of Learning and Memory, University of California, Irvine, CA 92717. tagonizes the amnestic effects of both morphine and $\beta$ endorphin (Baratti et al., 1984; Introini \& Baratti, 1984). These findings are in agreement with extensive neurochemical evidence indicating that opioid agonists inhibit acetylcholine release and that the inhibition is reversed by opioid antagonists (Jhamandas, Hron, \& Sutak, 1975; Jhamandas \& Sutak, 1974, 1983).

There is also extensive evidence indicating that the cholinergic system interacts with the adrenergic system in influencing memory storage. We recently found that atropine blocks the memory-enhancing effect of low doses of epinephrine, whereas the amnesia induced by high doses of epinephrine is completely blocked by oxotremorine and is partially attenuated by physostigmine (IntroiniCollison \& McGaugh, 1988).

The stria terminalis (ST) is a main afferent-efferent pathway of the amygdala (Cowan, Raisman, \& Powell, 1965; De Olmos, Ahleid, \& Beltramiro, 1985; De Olmos \& Ingram, 1972). The findings of previous studies indicate that lesions of the ST block the memory-enhancing effects of posttraining epinephrine (Liang \& McGaugh, $1983 b)$ and naloxone, as well as $\beta$-endorphin-induced amnesia (McGaugh, Introini-Collison, Juler, \& Izquierdo, 1986). In view of the evidence that both epinephrine and opioid peptides interact with the cholinergic system in modulating memory storage, the present experiments were undertaken to determine whether the effects of cholinergic drugs on memory storage also involve the ST.

\section{METHOD}

\section{Subjects}

Male Sprague-Dawley rats ( $180 \mathrm{~g}, 60$ days old; Charles River Laboratories) were individually housed upon arrival and maintained on a 12-h light/dark cycle (lights on at 7:00 a.m.) with food and water available ad lib. 


\section{Surgery}

Approximately 1 week after arrival, stereotaxic surgery was performed under ketamine anesthesia $(100 \mathrm{mg} / \mathrm{kg}$ i.p.) on rats pretreated with atropine $(0.5 \mathrm{mg} / \mathrm{kg}$ i.p.) and xylazine $(5 \mathrm{mg} / \mathrm{kg}$ i.p.): approximately half of the animals received bilateral ST lesions and half received sham lesions. The ST lesions were produced by radio-frequency current $(1.5 \mathrm{~V}, 20 \mathrm{sec}$; Grass Instruments Model LM-3) administered through bipolar electrodes (twisted, paired stainless steel wires with tips $0.5 \mathrm{~mm}$ apart, insulated except for the $0.5 \mathrm{~mm}$ at the tip) at brain coordinates AP $-0.5 \mathrm{~mm}$ from bregma, ML $\pm 2.5 \mathrm{~mm}, \mathrm{DV}-4.1 \mathrm{~mm}$ from the dura, nose bar elevated $0.5 \mathrm{~mm}$ (McGaugh et al., 1986). Sham lesions followed the same procedure except that the electrodes were lowered to DV $-3.5 \mathrm{~mm}$ below the dura and no current was passed. Skull bones were sealed with wax and Gelfoam.

\section{Inhibitory-Avoidance Training}

One week after surgery, the rats were trained on a trough-shaped inhibitory-avoidance (IA) apparatus (McGaugh et al., 1986) consisting of two compartments separated by a sliding door that opened by retracting into the floor. The starting compartment was illuminated by a tensor lamp, which provided the only illumination in the testing room. On the training trial, each rat was placed in the lighted compartment, facing the closed door. When the rat turned around, the door leading to the dark compartment was opened. In previous research, we have determined that these procedures reduce the variability in response latencies. When the rat stepped through the door into the dark compartment, the door was closed, a footshock $(0.35 \mathrm{~mA}, 60 \mathrm{~Hz})$ was delivered, and the response latency was recorded. A footshock duration of $0.7 \mathrm{sec}$ was used in the experiment examining the memory-enhancing effect of oxotremorine, whereas a footshock duration of $2.0 \mathrm{sec}$ was used to assess the memory-impairing effects of atropine. These procedures were used to avoid possible floor and ceiling effects in assessing the effects of the drugs on retention performance. Following the training trial, the rat was immediately removed from the apparatus and injected as described below. On the retention test 1 week later, the rat was placed in the lighted compartment as on the training session and the step-through latency (maximum of $600 \mathrm{sec}$ ) was recorded (McGaugh et al., 1986).

\section{Y-Maze Discrimination Training}

One week later, the rats were assigned to new treatment groups and trained on a Y-maze discrimination (YMD) task. The left alley of the Y-maze was illuminated, and the rat was trained to enter the left alley to escape from a footshock as described below. On the first trial, the rat was placed in the start alley and the sliding door of this alley was opened while the door leading to the right alley remained closed. Following a 10-sec delay, a footshock was delivered and remained on until the rat entered the left arm. The rat was then replaced in the start compartment after an intertrial interval of $40 \mathrm{sec}$. On the second trial, the door to the left alley was closed so that the rat was forced to enter the right (dark) alley, where it received a footshock. Immediately after entering the dark alley, the sliding door was closed and the rat was removed and placed in the start compartment. On subsequent trials (20-sec intertrial intervals), the rat was allowed to choose between the alleys, and each trial was terminated when the rat entered the left alley. If a rat failed to enter the left alley within $60 \mathrm{sec}$, it was placed in the left alley and retained there for $20 \mathrm{sec}$. Training was continued until the rat chose the lighted arm on three consecutive trials. The rat was then removed and immediately injected as described below. The nominal footshock intensity (i.e., read from meter) was $0.85 \mathrm{~mA}$. The shock source used in the study investigating the effects of oxotremorine was replaced by a new one prior to the study of the effects of atropine. Although the nominal footshock intensity was the same in the two studies, it was clear from the animals' responses to the shock (as well as the retention scores of control animals) that the new shock source produced a higher effective footshock level.

Retention was assessed 1 week later. The procedures used for the retention test were similar to those in the original training, except that the position of the safe alley was reversed - that is, the animal could escape from the shock only by entering the right (dark) alley. Each rat was given six trials (20-sec intertrial interval) with both alleys open. The number of errors made on the reversal-training trials was used as the measure of retention. The use of this procedure to assess retention was based on the assumption that retention of the original task impairs acquisition of the reversed discrimination. Furthermore, in previous work using this task, we have found that if the discrimination is not reversed-that is, if the animals are simply retrained on the original discrimination-the animals make very few errors and, consequently, the task is insensitive to memoryenhancing treatments (McGaugh et al., 1986).

\section{Drugs and Experimental Groups}

Immediately after training on both the IA and the YMD tasks, the rats were injected i.p. with saline, oxotremorine sesquifumarate (Sigma; $50 \mu \mathrm{g} / \mathrm{kg}$ ), or atropine sulfate (Sigma; $3.0 \mathrm{mg} / \mathrm{kg}$ ). The drugs were dissolved in saline to a volume of $1 \mathrm{ml} / \mathrm{kg}$. Doses are expressed as the base.

\section{Histology}

Lesions were verified histologically. All rats with ST or sham lesions were sacrificed by an overdose of pentobarbital $(100 \mathrm{mg} / \mathrm{kg}$ i.p.) and perfused with physiological saline solution $(0.9 \%)$ followed by formalin $(10 \%)$. The brains were removed immediately afterward, stored in (10\%) formalin at least $48 \mathrm{~h}$, and sliced $(40 \mu \mathrm{m})$. The slices were stained with cresyl violet. The tissues were examined for location of the lesions, blindly with respect to both treatment and behavioral performance. Behavioral data of rats with lesions that either missed the ST or invaded adjacent areas (e.g., the fimbria-fornix) were excluded from the final analysis. Animals were included only if the ST was substantially lesioned bilaterally in one of the coronal sections within AP 0.4 to AP -1.0. The extent of the maximum and minimum lesions of the animals included are shown in Figure 1.

\section{Statistical Analysis}

Data obtained in the IA task are expressed as median and interquartile ranges, and data obtained in the YMD task are expressed as the mean $\pm S E M$. Statistical analysis was performed with ANOVAs, and $p$ values of less than .05 were considered significant. The number of animals per group is indicated in the figure legends.

\section{RESULTS}

Figures 2 and 3 show the results obtained with animals injected with oxotremorine following training in the IA and YMD tasks, respectively. In both cases, the ANOVAs indicated significant differences among the groups [IA, $F(3,30)=6.3, p<.002 ; \mathrm{YMD}, F(3,35)=5.4, p<$ $.005]$. In both tasks, posttraining administration of oxotremorine significantly enhanced retention in the shamoperated rats ( $p<.01$ in both cases). ST lesions completely blocked oxotremorine-induced memory facilitation in both tasks. As a consequence, the interactions between the lesion and drug treatments were statistically 


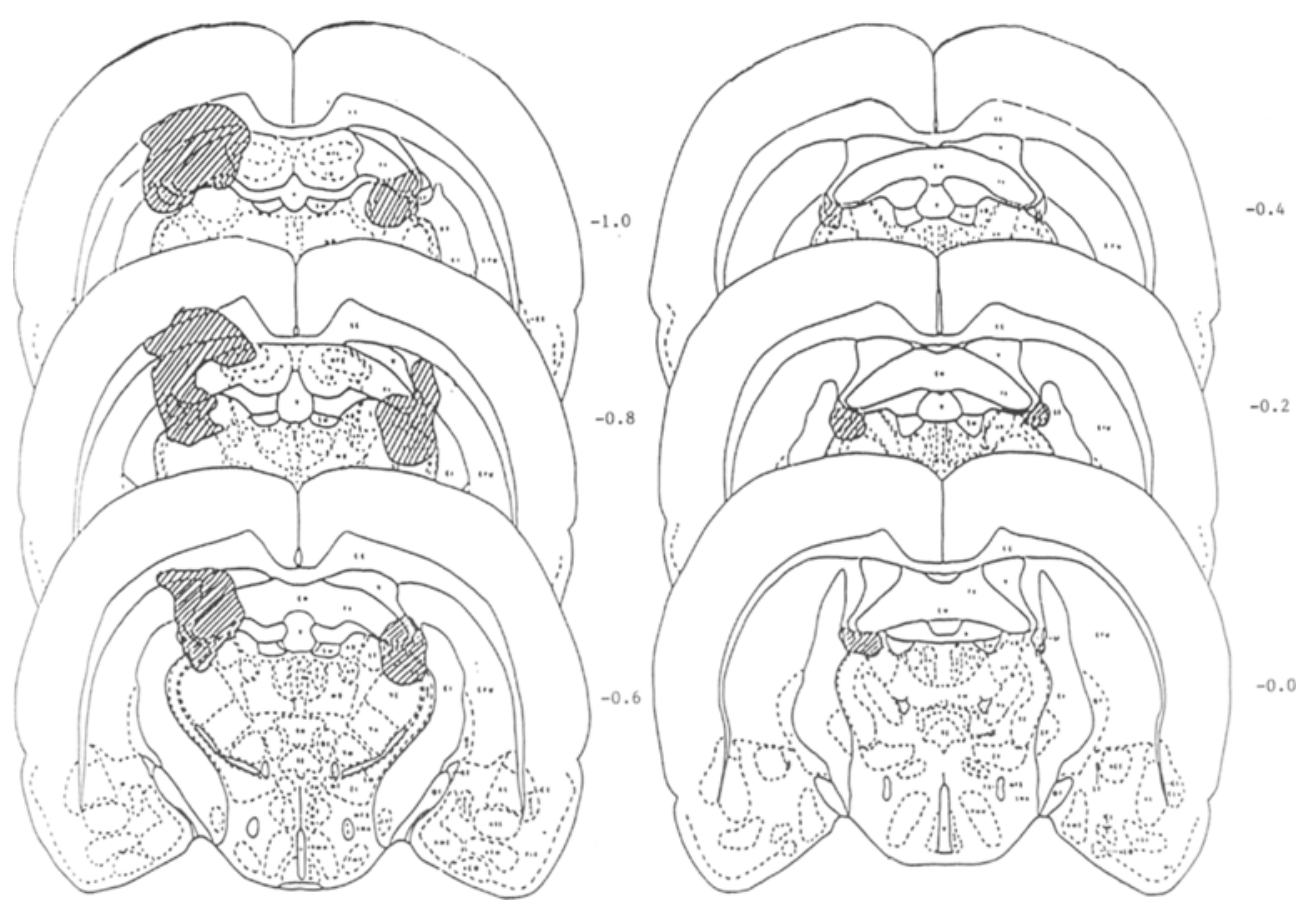

Figure 1. Maximum (left) and minimum (right) stria terminalis lesions in successive coronal sections (From A stereotaxic atlas of the rat brain, by L. J. Pellegrino, A. S. Pellegrino, and A. J. Cushman, 1979, New York: Plenum. Copyright 1979 by Plenum Press. Reprinted by permission.)

significant [IA, $F=9.2, p<.005 ;$ YMD, $F=4.4$, $p<.05)$.

Figures 4 and 5 show the results obtained with animals injected with atropine following training in the IA and YMD tasks, respectively. On both cases, the ANOVAs indicated significant differences among the groups [IA, $F(3,36)=27.4, p<.0001 ; \mathrm{YMD}, F(3,36)=12.1, p<$ $.0001]$. In both tasks, posttraining administration of atropine significantly impaired retention in the sham-operated

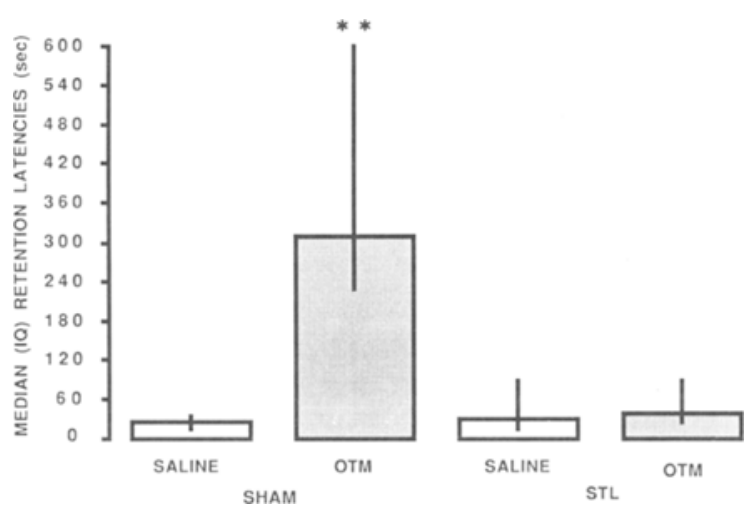

Figure 2. Effects of posttraining oxotremorine $(50 \mu \mathrm{g} / \mathrm{kg})$ on stepthrough inhibitory-avoidance (IA) retention in sham-operated and stria terminalis-lesioned rats. One week following surgery, rats were trained on the IA task then given pesttraining injections of saline or oxotremorine. They were tested for retention 1 week later. ${ }^{* *} p<.01$ as compared with the other groups. $N=10-14$ rats per group. rats $(p<.01$ in both cases). ST lesions completely blocked atropine-induced amnesia in both tasks. As a consequence, the interactions between the lesion and drug treatments were statistically significant (IA, $F=35.5$, $p<.0001 ; \mathrm{YMD}, F=11.0, p<.005$ ).

\section{DISCUSSION}

The present results are consistent with extensive evidence indicating that muscarinic cholinergic agonists generally facilitate memory (Dunnett, 1985; Flood et al., 1983, 1984, 1985; Introini-Collison \& McGaugh, 1988; Murray \& Fibiger, 1985), whereas muscarinic blockers typically induce amnesia (Blozovski \& Dumery, 1984; Elrod \& Buccafusco, 1988; Introini-Collison \& McGaugh, 1988; Lo Conte, Bartolini, Casamenti, MarconciniPepeu, \& Pepeu, 1982; Wirsching, Beninger, Jhamandas, Boegman, \& El-Defrawy, 1984). In both the IA and the YMD tasks, posttraining systemic administration of oxotremorine enhanced retention, whereas atropine impaired retention. Furthermore, the findings indicating that the effects of both oxotremorine and atropine require an intact ST indicate that the amygdala is involved in the action of cholinergic systems in memory modulation. These results are consistent with the findings of Blozovski and Dumery (1984) indicating that, in young rats, retention is impaired by atropine injected into the basolateral nucleus of the amygdala prior to training. It is of interest to note that for both the memory-enhancing effects of oxotremorine and the memory-impairing effects of atropine, 


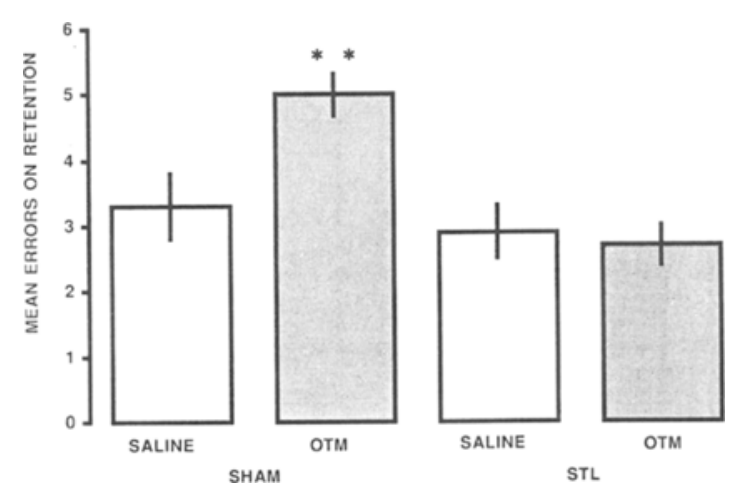

Figure 3. Effects of posttraining oxotremorine $(50 \mu \mathrm{g} / \mathrm{kg})$ on retention of a Y-maze discrimination (YMD) task in sham-operated and stria terminalis-lesioned rats. One week after completion of inhibitory-avoidance testing, rats were trained in the YMD task and given posttraining injections of saline or oxotremorine. Retention was tested 1 week later. ${ }^{* *} p<.01$ as compared with the other groups. $N=10-12$ rats per group.

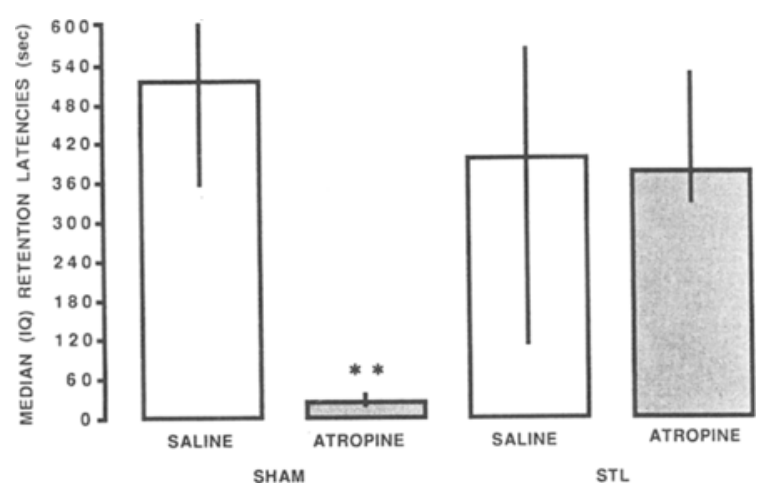

Figure 4. Effects of posttraining atropine $(3.0 \mathrm{mg} / \mathrm{kg})$ on stepthrough inhibitory-avoidance (IA) retention in sham-operated and stria terminalis-lesioned rats. One week following surgery, rats were trained on the IA task then given posttraining injections of saline or atropine. They were tested for retention 1 week later. ${ }^{* *} p<.01$ as compared with the other groups. $N=10-14$ rats per group.

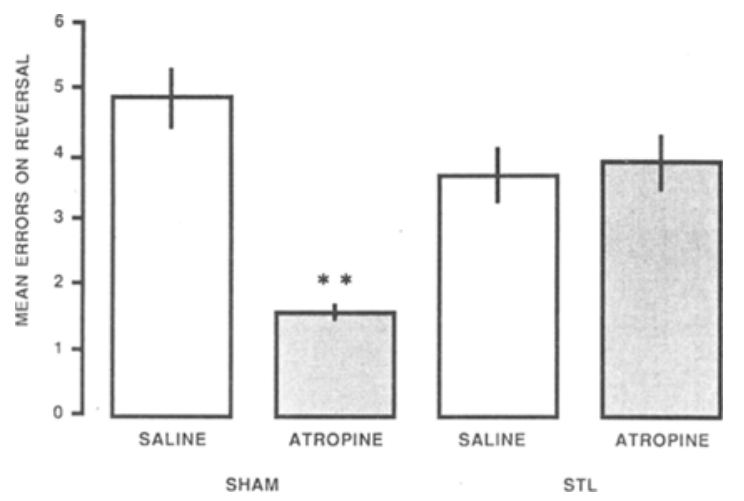

Figure 5. Effects of posttraining atropine $(3.0 \mathrm{mg} / \mathrm{kg})$ on retention of a Y-maze discrimination (YMD) task in sham-operated and stria terminalis-lesioned rats. One week after completion of inhibitory-avoidance testing, rats were trained in the YMD task and given posttraining injections of saline or atropine. Retention was tested 1 week later. ** $p<.01$ as compared with the other groups. $N=10-12$ rats per group. findings comparable to those reported above were obtained even if animals with larger lesions (which invaded the fimbria-fornix) were included in the analyses. (These analyses are not reported in the Results section.)

Previous findings indicate that ST lesions also block the impairing effects of posttraining electrical stimulation of the amygdala (Liang \& McGaugh, 1983a) as well as the memory-enhancing effects of systemically administered epinephrine (Liang \& McGaugh, 1983b). Other findings from our laboratory suggest that the effects of epinephrine on memory involve the release of acetylcholine (IntroiniCollison \& McGaugh, 1988). We have also found that ST lesions block both the memory-enhancing effects of naloxone and the impairing effects of $\beta$-endorphin (McGaugh et al., 1986). Furthermore, lesions of the ST also block the memory-enhancing effects of intraamygdala injections of norepinephrine (Liang, McGaugh, \& Yao, 1989).

In the present experiments, the drugs were injected systemically. Thus, we do not know whether the site of action of the drugs involves cholinergic receptors within the amygdala (Blozovski \& Dumery, 1984) or at loci in other brain regions. Lesions of the ST might attenuate the memory-modulating effects of the drugs either by blocking inputs from, or by blocking outputs to, cholinergic systems. The memory-modulating effects of the drugs may be mediated by influences on the amygdala or may simply require an intact amygdala. In view of the evidence that ST lesions block the memory-modulating influences of a variety of posttraining treatments, including brain stimulation as well as drugs affecting several neuromodulatory systems, it seems possible that the amygdala is a site of integration of neuromodulatory influences on memory storage. This view is consistent with other evidence indicating that memory storage can be modulated by posttraining intra-amygdala injections of agonists and antagonists affecting a variety of receptor systems (Brioni, Nagahara, \& McGaugh, 1989; Gallagher \& Kapp, 1978, 1981; Introini-Collison, Nagahara, \& McGaugh, 1989; Kesner, 1981; McGaugh, Introini-Collison, \& Nagahara, 1988).

\section{REFERENCES}

Baratti, C. M., Introini, I. B., \& Huygens, P. (1984). Possible interaction between central cholinergic muscarinic and opioid peptidergic systems during memory consolidation in mice. Behavioral \& Neural Biology, 40, 155-169.

Bartus, R. T., DeAn, R. L., Goss, J. A., \& LiPPA, A. S. (1980). Agerelated changes in passive avoidance retention: Modulation with dietary choline. Science, 209, 301-313.

Bartus, R. T., Dean, R. L., Pontecorvo, M. J., \&licker, C. (1985). The cholinergic hypothesis: A historical overview, current perspective, and future directions. In D. S. Olton, E. Gamzu, \& S. Corkin (Eds.), Memory dysfunctions: An integration of animal and human research from preclinical and clinical perspectives (pp. 332 358). New York: New York Academy of Sciences.

BLozovski, D., \& DUMERY, V. (1984). Implication of amygdaloid muscarinic cholinergic mechanisms in passive avoidance leaming in the developing rat. Behavioural Brain Research, 13, 97-106.

Brioni, J, D., Nagahara, A. H., \& McGaugh, J. L. (1989). Involvement of the amygdala GABAergic system in the modulation of memory storage. Brain Research, 487, 105-112. 
Cowan, W. M., Raisman, G., Powell, T. P. S. (1965). The connections of the amygdala. Journal of Neurology, Neurosurgery \& Psychiatry, 28, 13-15

DAvies, P. (1985). A critical review of the role of the cholinergic system in human memory and cognition. In D. S. Olton, E. Gamzu, \& S. Corkin (Eds.), Memory dysfunctions: An insegration of animal and human research from preclinical and clinical perspectives (pp. 212217). New York: New York Academy of Sciences.

De Olmos, J., Ahleid, G. F., Beltramiro, C. A. (1985). Amygdala. In G. Paxinos (Ed.), The rat nervous system (pp. 223-334). Sydney: Academic Press.

De Olmos, J. S., \& Ingram, W. R. (1972). The projection field of the stria terminalis in the rat brain: An experimental study. Journal of Comparative Neurology, 146, 303-334.

Drachman, D. A. (1977). Memory and cognitive function in man: Does the cholinergic system have a specific role? Neurology, 27, 783-790.

Drachman, D. A., Leavitt, J. (1974). Human memory and the cholinergic system. Archives of Neurology, 30, 113-121.

DUNNETT, S. B. (1985). Comparative effects of cholinergic drugs and lesions of nucleus basalis or fimbria-fornix on delayed matching in rats. Psychopharmacology, 87, 357-363.

ElRod, K., \&UCCAFUsco, J. J. (1988). An evaluation of the mechanism of scopolamine-induced impairment in two passive avoidance protocols. Pharmacology, Biochemistry \& Behavior, 29, 15-21

FlOOD, J. F., LANDRY, D. W., \& JarviK, M. E. (1981). Cholinergic receptor interactions and their effects on long-term memory processing. Brain Research, 215, 177-185.

Flood, J. F., Smith, G. E., \& Cherkin, A. (1983). Memory retention: Potentiation of cholinergic drug combinations in mice. Neurobiology of Aging, 4, 37-43.

Flood, J. F., Smith, G. E., \& Cherkin, A. (1984). Memory retention test performance in mice: Improvement by chronic oral cholinergic drug treatment. Pharmacology, Biochemistry \& Behavior, 21, 169-173.

Flood, J. F., SMITH, G. E., \& CHERKIN, A. (1985). Memory enhancement: Supra-additive effect of subcutaneous cholinergic drug combinations in mice. Psychopharmacology, 86, 61-67.

GALlaGHER, M., \& KaPP, B. S. (1978). Manipulation of opiate activity in the amygdala alters memory processes. Life Sciences, 23, 1973-1978.

Gallagher, M., \& KAPP, B. S. (1981). Effect of phentolamine administration into the amygdala complex of rats on time-dependent memory processes. Behavioral \& Neural Biology, 31, 90-95.

GOWER, A. J. (1987). Enhancement by secoverine and physostigmine of retention of passive avoidance response in mice. Psychopharmacology, 91, 326-329.

Haroutunian, V., Kanof, M. D., Davis, M. D. (1985). Pharmacological alleviation of cholinergic lesion induced memory deficits in rats. Life Sciences, 37, 945-952.

INTROINI, I. B., \& BARATti, C. M. (1984). The impairment of retention induced by beta endorphin in mice may be mediated by reduction of central cholinergic activity. Behavioral \& Neural Biology, 41, 152-163.

InTroini-Collison, I. B., \& McGaugh, J. L. (1988). Modulation of memory by posttraining epinephrine: Involvement of cholinergic mechanisms. Psychopharmacology, 94, 379-385.

Introini-Collison, I. B., Nagahara, A. H., \& McGaugh, J. L. (1989). Memory-enhancement with intra-amygdala posttraining naloxone is blocked by concurrent administration of propranolol. Brain Research, 476, 94-101.

Jhamandas, K., Hron, V., \& Sutak, M. (1975). Comparative effects of opiate agonists methadone, levorphanol and their isomers on the release of cortical acetylcholine in vivo and in vitro. Canadian Journal of Pharmacology \& Physiology, 53, 540-548.

JHAMANDAS, K., SUTAK, M. (1974). Modifications of brain acetylcholine release by morphine and its antagonists in normal and morphine-dependent rats. British Joumal of Pharmacology, 50, 57-62.

JHAMANDAS, K., SUTAK, M. (1983). Stereospecific enhancement of evoked release of brain acetylcholine by narcotic antagonists. British Journal of Pharmacology, 78, 433-440.

Karczmar, A. G., DUn, N. J. (1978). Cholinergic synapses: Physiological, pharmacological and behavior considerations. In M. A. Lipton, A. DiMascio, \& K. F. Killam (Eds.), Psychopharmacology: A generation of progress (pp. 293-305). New York: Raven.

KESNER, R. P. (1981). The role of the amygdala within an attribute analysis of memory. In Y. Ben-Ari (Ed.). The amygdaloid complex (pp. 331-342). Amsterdam: Elsevier/North Holland.

LiAnG, K. C., MCGAUGH, J. L. (1983a). Lesions of the stria terminalis attenuate the amnestic effect of amygdaloid stimulation of avoidance responses. Brain Research, 274, 309-318.

LiANG, K. C., MCGAUGH, J. L. (1983b). Lesions of the stria terminalis attenuate the enhancing effect of posttraining epinephrine on retention of an inhibitory avoidance response. Behavioural Brain Research, 9, 49-58.

LiAnG, K. C., McGaugh, J. L., \& Yo, H.-C. (in press). Involvement of amygdala pathways in the influence of posttraining amygdala norepinephrine and peripheral epinephrine on memory storage. Brain Research.

lo Conte, G., Bartolini, L., Casamenti, F., Marconcini-Pepeu, I., 2 PEPEU, G. (1982). Lesions of cholinergic forebrain nuclei: Changes in avoidance behavior and scopolamine actions. Pharmacology, Biochemistry \& Behavior, 17, 933-937.

MCGAUGH, J. L. (1989). Involvement of hormonal and neuromodulatory systems in the regulation of memory storage. Annual Review of Neuroscience, 12, 255-287.

MCGaugh, J. L., Introini-Collison, I. B., Juler, R. G., IzQUIERDO, I. (1986). Stria terminalis lesions attenuate the effects of posttraining naloxone and $\beta$ endorphin on retention. Behavioral Neuroscience, 100, 839-844.

McGaugh, J. L., Introini-Collison, I. B., Nagahara, A. H. (1988). Memory-enhancing effects of posttraining naloxone: Involvement of $\beta$-noradrenergic influences in the amygdaloid complex. Brain Research, 446, 37-49.

Murray, C. L., FibiGer, H. C. (1985). Learning and memory deficits after lesions of the nucleus basalis magnocellularis: Reversal by physostigmine. Neuroscience, 14, 1025-1032.

Pellegrino, L. J., Pellegrino, A. S., Cushman, A. J. (1979). A stereotaxic atlas of the rat brain. New York: Plenum.

RusseLL, R. W. (1982). Cholinergic systems in behavior: The search for the mechanisms of action. Annual Review of Pharmacology \& Toxicology, 22, 435-463.

Stratton, L. O., \& Petrinovich, L. F. (1963). Post-trial injections of an anticholinesterase drug and maze learning in two strains of rats. Psychopharmacologia (Berlin), 5, 47-54.

Wirsching, B. A., Beninger, J., Jhamandas, K., Boggman, R. J., * El-Defrawy, S. R. (1984). Differential effects of scopolamine on working and reference memory of rats in the radial maze. Pharmacology, Biochemistry \& Behavior, 20, 659-662.

(Manuscript received January 12, 1989; revision accepted for publication April 26, 1989.) 